\section{THE POINTS OF RESEMBLANCE BETWEEN CATTLE PLAGUE AND SMALL-POX. To the Editor of THE LANCEr.}

SIz,-Since I last addressed you, I have had the opportunity of repeating my observations on the alterations of the skin in cattle plague, in another series of experimental animals, in all of which the appearances have been carefully scrutinized from day to day; and, on Saturday last, I made a journey into the country for the purpose of examining, with the able cooperation of Mr. Duguid, Lecturer on Physiology in the New Veterinary College, thirty-five animals in various stages of the disease.

The appearances which present themselves during life may be designated as follows:-(1) Gamboge incrustation ; (2) separation of the superticial layers of the epidermis ; (3) formation of elevations of the surface, consisting of $(a)$ smooth tubercles or nodules, (b) smaller and more rapidly formed papules.

Of these appcarances, the first, the gamboge incrustation, is by far the most cominon. It occurs at an early period in the disease, not more than two or three days after the characteristic changes of the mucous membrane of the mouth, described by me at the Pathological Society, have commenced. The affected parts are at first unctuous to the touch, as if smeared with some greasy substance. In the course of a day or two this sebaceous secretion crusts upon the surface, assuming a pale-yellow colour, precisely sinilar to that of moistened gamboge.

The separation of the epithelium occurs somewhat later, and is dependent, as $I$ stated in my former letter, on the exuberant development of nuclear corpuscles at the surface of the corium. It is, I believe, always associated with hyperæmia of that structure, which in those parts in which the epidermis is thin and transparent communicates a red colour to the skin (socalled roseola). This appearance is met with only on the udder and around the vulva.

The smooth tubercles are found on dissection to be due to enlarged sebaceous glands choked with secretion. This material is liable to soften and become diffuent, in which case it assumes the character of an abscess below the cuticle, or acne pustule.* The papules consist of elevations of the cuticle around single a air-bulbs or groups of hair-bulbs; these, although they differ somewhat in different parts of the skin, have certain characters in common. On cutting into them they are found to have soft certtres, but firm superficial crusts ; on detaching these the hair-bulbs and sebaceous follicles to which they adhere are drawn out with them, and a moist and slightly reddened surface is left behind. They never yield any liquid juice or serum, but the encrusted hair-bulbs and follicles are found to be embedded in the same pulpy material, consisting of nuclear corpuscles, by which the loose epidermis is separated from the cutis. They are never surrounded with any areola, and never assume a vesicular form; they have not the most distant resemblance to the papules of small-pox.

The appearances above described are met with in the neighbourhood of the mouth, on the perineum, udder, and scrotum, and on the neck from the poll to the withers. In consequence of the anatomical peculiarities of the integument of the udder in milk cows, and particularly of its redness in glands, the alterations in question are more marked around the teats of these animals than in any other situation. In the thirty-five animals examined last saturday, all of which were heifers, excepting one, they occurred as follows:-The sebaceous gam boge-coloured incrustation was met with in some part of the body in thirty-one; it existed in a marked degree on the chin and around the mouth in thirteen, here forming, in some instances, a thick layer which, although bright yellow when dry, was white where moistened by the discharge from the mouth; on the skin of the neck it was abundant in seven animals, forming a continuous layer of firm consistence, by which the hair was matted together, but was entirely absent in twentyfive. On the soft skin of the inside of the thighs, the udder, and perineum, it was obvious in ten animals, but here it was apt to assume a furfuraceous character. The detachment of the epithelium around the vulva and near the corner of the mouth was observed in a few cases, in which the cutaneous surface of these parts had assumed a cracked or crumpled ap* These tubercles were not found in any of the animals examined on
Saturday. They are common on the udders of milk cows affected with the disease, but have no constant relation to rinderpest. pearance. The elevations which I have ventured to call papules were well marked in two animals, in the neighbourhood of the vulva, but were much more frequently met with on the chin and around the mouth ; in each instance they were carefully examined, and several of them cut into for the purpose of ascertaining that they contained no liquid.

I may mention that in every animal, with the exception of one that was convalescent, the alterations of the mucous membrane of the mouth which are pathoguomonic of rinderpest were observed.

During this laborious investigation, I could not help regretting that my friend Dr. Murchison was not present, for if he had been he would have seen that of the three elements of which he repeats in his article of last week that the "eruption in rinderpest" consists, not one was met with in any of the thirty-five animals examined. Neither "patches of roseola, pustules, nor petechiæe" could be discovered in any single instance. What, I ask, is the use of repeating over and over again the worn-out passage of Ramazzini about the "pustulæ ac tubercula variolarum species referentia" in support of a theoretical speculation, whereas the question might easily be settled by half-an-hour's attentive examination of the eruption as it presents itself cluring life?

I am, Sir, your obedient servant,

J. Burdon Sanderson, M.D.

Queen Anne-street, Jan. 15th, 1866

P.S. - There are now animals at the Albert Veterinary Col lege in various stages of rinderpest, by the inspection of which anyone may satisfy himself as to the accuracy of the above descriptions.

\section{"ENTOZOA" IN FLESH. To the Editor of Trre LANCET.}

Sir,-Dr. Fenwick was good enough to direct my attention. to his discovery of the so-called "Rainey's" bodies in the muscles, and especially in the hearts, of cows dead of cattle plague, some little time since, in fact several days before his letter on the subject appeared in The Times. I was then fully occupied with the preparation of my Report for the Royal Commissioners, and unable to investigate the matter for myself. I must confess, too, that, while not questioning the entire accuracy of Dr. Fen wick's observations, I did very much question (for reasons which it is scarcely necessary to specify) their importance, as tending to throw light on the nature and origin of the cattle plague.

Dr. Fenwick's letter seems, however, to have excited some little interest, and I have therefore felt it my duty, as soon as leisure and opportunity permitted, to investigate on my own account the question to which his letter relates. The results may be given in a very few words.

On Saturday last, I exannined the carcases of two heifers, dead of cattle plagne, at the Albert Veterinary College, and $I$ found Rainey's bodies in considerable abundance in all their muscles that I tested with the microscope, in the tongues, in the deep muscles of the neck, in the muscles of the abdominal walls, and especially in the muscular parietes of their hearts. Last night I bought three bullocks' hearts of a respectable butcher in my neighbourhood. I examined them carefully and in every case $I$ found (imbedded in the muscular fibres) the same species of parasite (Rainey's bodies) which I had found in the former cases, equally matured, and, so far as I could see, equally abundant.

Whether these bodies are animal or vegetable, I do not undertake to say, but there is no doubt that they are the bodies which Mr. Rainey described some years ago, and which at that time he believed to be immature cysticerci cellulosæ. I examined them with him, and have drawings of them by me. They are of much pathological interest, and still need elucida. tion, but obviously they have only an accidental connexion with the cattle plague.

I have hitherto refrained from taking part in the more important controversy which has been going on relative to the identity or non-identity of the cattle plague with human smallpox, and $I$ have thus refrained, chiefly because it has seemed to me somewhat out of order, if not injudicious, for those who are employed to investigate the cattle plagne to enter npon a controversy upon a point in connexion with it which their own investigations are intended to clear up, and which can only be cleared up by such investigations. I may take this opportunity, however, of saying a few words on the subject. No 
one acquainted with the morbid anatomy of small-pox could fail, on examining cows dead of cattle plague, to be struck with the close resemblance which exists between these two diseases in regard to their morbid anatomy. Allowing for the absence from the human being of the first three stomachs of the cow, the description of the internal lesions observable in the cattle plague might serve almost exactly for the description of the internal lesions in small-pox. This fact struck me at the very first post-mortem of a cow on which I was engaged, before even 1 had any suspicion that there was an eruption on the skin at all resembling that of small-pox. But I have since then examined the cutaneous eruption very carefully in a good many cases, and $I$ have no hesitation in asserting that the eruption, thongh resembling superficially that of small-pox, is essentially different from the eruption of small-pox, as that eruption has hitherto been known to me by observation and by reading, and is essentially different, too, from the eruption of vaccinia. I agree generally with the description of it which Dr. Sanderson has given. I've never yet seen a vesicle. I've never yet seen a pustule. I've never yet seen that destruction of the surface of the skin which in small pox leads to pitting.

It is quite certain that cattle plague has a very much closer resemblance to small-pox than to any other human disease with which we are acquainted; but resemblance and identity are two very different things. I incline decidedly to the belief that the two diseases are distinct, but I am very far indeed from asserting that they are so.

\section{I am, Sir, your obedient servant,}

J. S. BRIstowe, M.D.

Queen-square, Westminster, Jan. 16th, 1866.

** We very much regret that we are unable to publish this week a valuable communication of Dr. Cobbold, the leading authority on helminthology in this country, on the subject of "Spurious Entozoa in Diseased and Healthy Cattle." It arrived too late for insertion in this number, but shall appear next week. - ED. L

\section{ON THE TREATMENT OF TROPICAL HEPATITIS.}

To the Editor of 'THE LANCET.

Sir,-Although unwilling to prolong my controversy with Dr. Cameron or to tax the patience of your readers, permit me to offer the following brief summary of the points in dispute.

1. Dr. Cameron, in your pages, urged a return to the practice of exploring the liver in search of a purulent collection, with a view to its discharge through the abdominal parietes by means of an artificial opening.

I objected to this on the ground $(a)$ of my knowledge of the little success that attended the measure in Southern India in the hands of Inspector-General Murray, who revived, if he did not originate the practice, and the medical officers who were induced by him to perform the operation. (b) Because many abscesses in the liver tend naturally to discharge themselves through the lung, or into the stomach or bowels-points of issue which give a much larger proportion of recoveries than an external opening, whether that opening be made by Nature or by the trocar of a surgeon; clearly because in the latter case it is impossible to exclude the free admission of air into the suppurating cavity. (c) Because abscesses in the liver are frequently multiple, and because it is impossible for the most experienced physician to say beforehand whether the case be one of single or multiple abscess. (d) Because in an extensive field of personal experience, ranging over twenty-two years of service in Southern India and the malarious rivers of China, from Canton to Nankin, I had seen only unsatisfactory results follow the practice.

2. Dr. Cameron in a subsequent paper advocated the treatment of acute hepatitis by enormous bleedings, and urged this method of treatment by precept and example even in the cases of men advanced in life, and with constitutions depraved by long residence in a malarious climate and by intemperance. I also understood Dr. Cameron, and so did many others who read his paper, to say that suppurative inflammation of the liver is always ushered in by the acute and well-marked symptoms he described.

Now, I objected $(a)$ that there are two kinds of inflammation-viz., of the parenchyma and of the capsule. That the form which causes the most acute pain, tenderness on pressure, high fever, and suchlike symptoms, is, as a rule, that of the capsule, "perihepatitis," the capsular or adhesive inflammation of other authors-a form which does not tend to suppuration at all. (b) That in a large number of cases, occurring, I may add chiefly in malarious localities and in connexion with dysentery, suppuration takes place in a much more silent and insidious manner ; and it often happens that the urgent symptoms described by Dr. Cameron begin, not at the commencement, but at the end of the process, when pus previously formed making its way to the surface involves the capsule. The note-books of every physician of large tropical experience must be full of such cases. A late illustrious victim to the climate of India and to the crushing anxieties of public life, within three days of his death declared that he had not a single uneasy sensation in the right hypochondrium, and yet, after his death, the liver was found to be the seat, not of one but several abscesses.

Dr. Cameron assumes, because I say that the enormous bleedings he urges are not based on sound views, that therefore the practice I advocate is that "of waiting to see what will turn up." Your readers will not fail at all events to "see" that this is a mere assertion on Dr. Cameron's part. Those who are familiar with my practice and teaching will take the assertion at its proper value.

I have not the least expectation that anything I can say is at all likely to convince Dr. Cameron; but I ask you to give space to this my last communication on the subject, in order that those who take an interest in this question may learn my opinions from myself, and not through the distorting medium of Dr. Cameron's last letter. I am, Sir, faithfully yours

Netley Hospital, Jan. 1866. W. C. Maclean, M.D.

\section{POOR-LAW MEDICAL REFORM. \\ To the Editor of The LANCET.}

Sin, - Since the last report published in your journal I have received $\mathfrak{E} 73 s .6$., as the annexed list will show, which has not only placed the Association out of debt, but leaves a small surplus fur future proceedings. To this surplus I trust the Poor-law medical officers generally will add their subscriptions, and thus enable the Association to take active proceedings during the ensuing session of Parliament.

There is a question now before the country to which I desire to call the attention of the Poor-law medical officersviz., "the rinderpest," which, should it be proved to be a malignant form of small-pox, will compel the Government to consider the question of the compulsory vaccination of all calves not to be killed as such, and thus prevent the spread or reappearance of the rinderpest in the United Kingdom. Should such be the case, and the Poor-law medical officers not consider it derogatory to vaccinate these animals in their respective districts, a very material addition might be made to their at present miserable incomes; besides this, it would be the means of leeping up the supply of lymph for the human subject. If, however, they should decline to do this I feel certain that those who are deputed to vaccinate the calf (a much more difficult operation than that in the human subject) will after a time vaceinate the infant, and thus a material reduction instead of an increase may be made in the incomes of the Poorlaw medical officers. I throw this out for the consideration of my brethren, that steps may be taken to insure the attainment of this object should they desire it.

R. Griffin, Weymouth, 21s.; H. T. Matthews, Horsham, 21s.; C. F. Lewis, Horsham, 5s.; W. Martin, Horsham, 10s.; R. Harrison, Kendall, 5s.; A. Cheeves, St. Germains, 5s.; H. E. Sargent, Launceston, 5s.; H. B. Goold and W. B. Norman, Portsea Island, 10s.; W. A. Raper, Portsea Island, 5s.; J. Allnutt, Portsea Island, 5s. ; J. E. Brine, Shaftesbury, $21 s$; T. H. Swaine, 10s.; W. H. R. Bennett, 10s.; J. S. Miles, $10 s$. Royal-terrace, Weymouth, I am, Sir, yours, \&c., Jan. 13th, 1866. RICHARD GRIFFIN.

Association FOR THE IMPROVEMENT OF THE CONDItTon of the Sick PoOr IN THE Metropolitan WorkHouses. - An association, with the above title, is in process of formation. With a view to the furtherance of this object it is proposed that a public meeting be called early in February. The temporary honorary secretaries for the purpose of organization are-Mr. Ernest Hart, 69, Wimpolestreet ; Dr. Anstie, 16, Wimpole-street ; and Dr. Rogers, 33, Dean-street, Soho. Mr. John S. Storr, 26, King-street, Covent-garden, is treasurer pro tem., with either of whom gentlemen willing to give their aid are requested to communicate. 